\title{
Bacteriorhodopsins extracted from Halobacterium may be useful to absorb cyan and green light (exceptional to reduce scars due to acne ribelle) and couperose
}

\author{
Piotr Brzeziński', Lorenzo Martini ${ }^{1,2}$
}

${ }^{1}$ University of Siena, Department of Pharmaceutical Biotechnologies, Via A. Moro 2, 53100 Siena, Italy, ${ }^{2}$ C.R.I.S.M.A. Inter

University Centre for Researched Advanced Medical Systems

Corresponding author: Prof. Lorenzo Martini, E-mail: martini36@unisi.it

\begin{abstract}
The bacteriorhodopsins, extracted from Halobacteria, Gram - bacteria commensal of the salts of strong saline lakes or seas, when undergo some special methods of biotransformation, are capable to absorb at 495-570 nm, and thus the cyan and green light that are beneficial for several diseases and malaises of skin in men, women of whichever age (cicatrixes evoked by acne ribelle, couperose and thesaurismosis or black spots of the face skin and hands (because of sun exposure of physiological senescence). The AA have created a gélée apt to absorb these kinds of radiations and demonstrated that after three weeks of treatment the causes of blemishes and imperfections of the epidermal layer. It is suggestive the fact that one of the volunteers, suffering from a severe couperose, has experimented this cosmetic gélée, albeit he continued to assume alcohol and sinefrine, that are vasodilator agents as well. Results are encouraging and satisfactory.
\end{abstract}

Key words: Bacteriorhodopsins; Archaea; Pyrogenic silica; Acne ribelle; Cyan light; Green light

\section{INTRODUCTION}

Halobacteria, members of the domain Archaea, live under extremely halophilic conditions [1]. They are found in strongly saline lakes (such as the Great Salt Lake, the Dead Sea, or the alkaline, saline lakes of East Africa) and also in the worldwide salters where salt is commercially produced from seawater by evaporation. The first bacterial retinal-containing protein, the lightdriven proton pump bacteriorhodopsin (BR) was found in Halobacterium halobium [2,3]. Since then, halorhodopsin (HR) with a light-driven chloride pump and two pigments with sensory functions, sensory rhodopsin (SR) and phoborhodopsin (PR) (or sensory rhodopsin-11) have also been found in H. halobium (Oesterhelt \& Stoeckenius, 1971; Matsuno-Yagi \& Mukohata, 1977; Bogomolni \& Spudich, 1982; Tomioka et al., 1986a). Recently, these bacterial rhodopsins have been found in other halobacterial species, such as archaerhodopsin in halobacteria from Australia, and halorhodopsin- and phoborhodopsin-like pigments in the haloalkalophile Nutrombacteriumpharaonis (Mukohata et al., 1988; Bivin \& Stoeckenius, 1986; Duschl et al., 1990). The bacterial rhodopsin family is continuing to grow $[4,5]$.

Bacteriorhodopsis absorb at 495-570 nm (cyan and green light).

Now it is indisputable that:

Cyan (light blue) calms and soothes irritated skin and helps to reduce the size of capillaries.

Green light is reputed exceptional to treat hyperpigmentation from sun damage or old post inflammatory pigmentation left from acne.

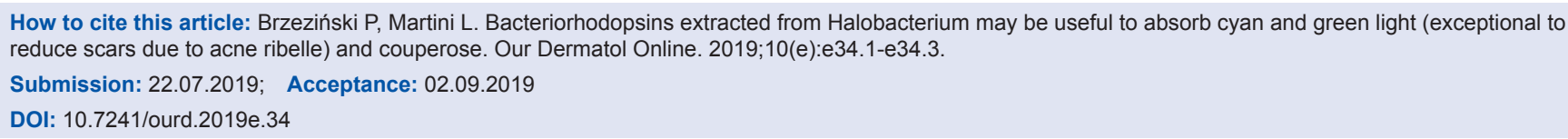




\section{MATERIALS AND METHODS}

It must be considered that in the INCI the Bacteriorhodopsin (CAS: 53026-44-1 and molecular weight: $26,784 \mathrm{kDa}$ ) is described as Bacteriorhodopsin from Halobacterium salinarum and therefore is already admitted as cosmetic ingredient.

The isolation and characterization of new halobacteria has been driven from crude solar salts (from Dead Sea).(4-5) The salts $(-100 \mathrm{mg})$ were first dissolved in a complex medium used for growth of $\mathrm{H}$. halobium (Oesterhelt \& Stoeckenius, 1974). After shaking vigorously for 6-8 d at 40 "C, the cultures were diluted about 1000 times with the medium and the dilutions were plated on complex medium solidified with $1.5 \%$ agar (Difco). Discrete red-purple coloured colonies were picked and inoculated into the complex liquid media. After 6-8 d growth, culture solutions were diluted, plated on the agar medium and discrete colonies picked. The cells from well-isolated colonies on the third liquid-culturing and plating were observed microscopically and checked for purity. Seven different isolates were obtained from the five different solar salts. The cell shape and the motility of the isolates were monitored with infrared illumination selected by an infrared transmitting filter (Hoya IR-76) from a $12 \mathrm{~V}$ $50 \mathrm{~W}$ tungsten-halogen lamp beam (Philips 7023) and an infrared sensitive video camera (Sony XC-37) mounted on the phase contrast microscope (Nikon Optiphot XF-Ph). Growth of cells and preparation of cell envelope vesicles. Newly isolated strains $\mathrm{H}$. halobium Rl and ONl-bW were grown in the complex synthetic medium for 6-8 d. Because cells in early exponential growth phase contain larger amounts of PR than do stationary phase cells, cultures were used for the detection of PR-like pigment after $2 \mathrm{~d}$ growth. Cells were collected by centrifugation (8OOO g, $15 \mathrm{~min}$ ) and resuspended in $4 \mathrm{M}-\mathrm{NaCl}$ containing DNAase. Cell envelope vesicles were prepared by the freezethaw method. Resuspended cells were frozen at - 80 "C overnight and thawed at room temperature. The suspension was washed with $4 \mathrm{M}-\mathrm{NaCl}$ three times by centrifugation $(20000 \mathrm{~g}, 30 \mathrm{~min})$. The envelope vesicles were further fractionated on a Ficoll density step gradient $(25,10$ and $5 \%, \mathrm{w} / \mathrm{w})$ and the fraction between $10 \%$ and $5 \%$ was used for measurements of light-induced ion pump activities. In this preparation, the right-sidesut envelope vesicles were mainly obtained as described (Li et al., 1986). Protein concentration was determined by the Lowry method with bacteriorhodopsin as a standard [6,7].
The bacteriorhodopsins derived from Halobacterium salinarum is a big protein chain and it has resulted very difficult to find an optimal solubility in cosmetic solvents, but the only one has been an ancient gélée prepared by heating pyrogenic silica in vegetable oil (Sesamum indicum oil) [8-10].

The AA has ideated this gélée dispersing the rhodopsins $(2.4 \%)$ in the cosmetic system based on silica and Sesamum indicum oil.

They have recruited three volunteers:

a) An old lady suffering from black spots on her face and hands, due to senescence and abuse of sun exposure during her life

b) A young man presenting cicatrixes evoked by an acne ribelle not well treated prior.

c) A middle age man suffering from couperose on their cheekbones evoked by abuse of alcohol, caffeine and sinefrin to loose weight.

The applications of the gélée containing rhodopsins lasted three weeks and results are especially satisfactory.

\section{RESULTS}

After three weeks it has been possible to behold that Case a did not show anymore black spots on her face and hands, the face skin of the young man (case b) was smooth and sheer and finally the case c, the man presenting a dramatic couperose, showed a pinkish, clear and brighting skin, even if he continued to consume alcohol during all the duration of the treatment.

\section{Statement of Human and Animal Rights}

All procedures followed were in accordance with the ethical standards of the responsible committee on human experimentation (institutional and national) and with the Helsinki Declaration of 1975 , as revised in 2008 .

\section{Statement of Informed Consent}

Informed consent was obtained from all patients for being included in the study.

\section{REFERENCES}

1. Shiladitya D. Extreme Microbes. Am Scien. 2007;95:224-31.

2. Nicholls DG, Ferguson SJ. Bioenergetics 2 (2 ${ }^{\text {nd }}$ ed.).1992: San Diego: 


\section{www.odermatol.com}

Academic Press.

3. Berg JM, Stryer L, Tymoczko JL. Biochemistry. 2015. New York - Basingstoke: W. H. Freeman Ed. $8^{\text {th }}$ ed.

4. Iwata S, Kinosita Y, Uchida N, Nakane D, Nishizaka T. Motor torque measurement of Halobacterium salinarum archaellar suggests a general model for ATP-driven rotary motors. Commun Biol. 2019;2:199.

5. Jeganathan C, Thamaraiselvi K, Sabari Girisun TC. Improved production of bacteriorhodopsin from Halobacterium salinarum through direct amino acid supplement in the basal medium. Extremophiles. 2019;23:133-9.

6. Mescher MF, Strominger JL. Purification and characterization of a prokaryotic glucoprotein from the cell envelope of Halobacterium salinarium. J Biol Chem. 1976;251:2005.

7. Tomioka H, Sasabe H. Bacterial rhodopsins of newly isolated halobacteria. J Gen Microbiol. 1992;138:1027-37.

8. Balsam MS, Sagarin E. Cosmetics, Science and Technology;1992:
Krieger Pub Co; $2^{\text {nd }}$ Ed., Malabar, Florida (US).

9. Dai G, Geng X, Chaoluomeng, Tamogami J, Kikukawa T, Demura M, et al. Photocycle of Sensory Rhodopsin II from Halobacterium salinarum (HsSRII): Mutation of D103 Accelerates M Decay and Changes the Decay Pathway of a 13-cis O-like Species. Photochem Photobiol. 2018;94:705-14.

10. Dossa K, Mmadi MA, Zhou R, Zhang T, Su R, Zhang Y, et al. Depicting the Core Transcriptome Modulating Multiple Abiotic Stresses Responses in Sesame (Sesamum indicum L.). Int J Mol Sci. 2019;20.pii: E3930.

Copyright by Piotr Brzeziński, et al. This is an open-access article distributed under the terms of the Creative Commons Attribution License, which permits unrestricted use, distribution, and reproduction in any medium, provided the original author and source are credited.

Source of Support: Nil, Conflict of Interest: None declared. 